\title{
A retrospective investigation of twenty-five cases with periocular pilomatrixoma
}

\section{Wei Song ( $\nabla$ wsongzj@163.com )}

Jiaxing Traditional Chinese Medicine Hospital https://orcid.org/0000-0002-0739-3615

\section{Zhenyi Ma}

\author{
Jiaxing Hospital of Traditional Chinese Medicine
}

\section{Research Article}

Keywords: pilomatrixoma, periocular, eyelid, eyebrow

Posted Date: March 9th, 2021

DOl: https://doi.org/10.21203/rs.3.rs-178314/v1

License: (9) This work is licensed under a Creative Commons Attribution 4.0 International License. Read Full License 


\section{Abstract \\ Purpose}

Pilomatrixoma is an uncommon benign skin tumor, developing from hair follicle matrix. It consistently presents in the head and neck region patients with pediatric predominance, from infancy to senior. Thus far, few case series studies have been focused on the periocular lesions that involve the eyelid and eyebrow. In the present study, we carried out a case series with 25 patients of periocular pilomatrixoma.

\section{Methods}

Records from the Hospital Information System (HIS) of our hospital were reviewed retrospectively between the years 2009 and 2020 to search for all patients that were diagnosed as pilomatrixoma of eyelid or eyebrow. All patients received excision in the Department of Ophthalmology and histological examinations in the Department of Pathology. Patients' information and characterization of tumors features were recorded and analyzed.

\section{Results}

These clinical conditions were mostly found in female patients in their early twenties. All tumors developed at upper eyelids or eyebrows and both right and left sides were equally affected. Basophilic cells and shadow cells were the basic components of the lesions, with or without calcification and foreign body giant cells. Complete surgical resection was the essential therapeutical approach for this disease and no recurrence or malignant transformations were noticed upon follow-up.

\section{Conclusion}

The findings of current case series analysis are in concordance with the clinical and histopathological features of periocular pilomatrixoma.

\section{Introduction}

Pilomatrixoma, a rare hair follicle matrix-derived benign tumor, always presents in the head and neck in pediatric populations[1]. In 1880, Malherbe and Chenantais first described it as "calcifying epithelioma of Malherbe". In 1949, Lever and Griesemer found the calcifying epithelioma arising from immature hair matrix cells[2]. In 1961, Forbis and Helwig used the term "pilomatrixoma" instead of previous "calcifying epithelioma" since they noticed the tumor developing from primitive epidermal germ cells that are differentiating toward hair matrix cells[3]. 
With the incidence of around $1 \%$ among benign skin lesions[4], pilomatrixoma is an uncommon lesion that presents at periocular regions, such as eyelid and eyebrow. Clinically, the diagnosis of periocular pilomatrixoma is somehow difficult given the similarity of their appearance to other dermal masses, such as chalazion $[5,6]$. Therefore, histological examinations upon complete surgical resection are essential for the confirmation of such conditions[1].

Till now, most of the periocular pilomatrixoma are reported as case reports around the world. In English literatures, we noticed that two case series investigations of more than 10 patients have been reported in Israel[ $[7,8]$. Another study of 13 cases of pilomatrixoma of the ocular adnexae was reported in German[9]. In the present study, we aimed for the first time to present a relatively large case series of periocular pilomatrixoma from one ophthalmic clinic in order to show the clinical and histopathological characteristics of such clinical condition in China.

\section{Methods}

Records from the Hospital Information System (HIS) of our hospital were reviewed retrospectively between the years 2009 and 2020 to search for all patients that were diagnosed as pilomatrixoma of eyelid or eyebrow. All patients received excision in the Department of Ophthalmology and histological examinations in the Department of Pathology. Patients' information includes gender and age, characterization of tumors features includes location, gross appearance, size (diameter in large), development duration, histopathological characteristics were recorded and analyzed. For histopathological examinations, all excised biopsies were sectioned and stained with hematoxylin and eosin. This study was adhered to the principles listed in the Declaration of Helsinki and was approved by the Ethics Committee of our hospital.

\section{Results}

Demographic data of patients

Totally 25 patients of periocular pilomatrixoma received excision in our department from 2009 to 2020 . Age at the time of diagnosis ranged from 3 to 70 years (mean 25 years, median 15 years). There were 14 female patients (56\%) and 14 patients (56\%) younger than 20 years. The demographic data of all patients were listed in Table 1. 
Table 1

The demographic data of patients and clinical characteristics of lesions

\begin{tabular}{|c|c|c|c|c|c|c|c|}
\hline No. & Gender & $\begin{array}{l}\text { Age } \\
\text { (years) }\end{array}$ & $\begin{array}{l}\text { Duration } \\
\text { (months) }\end{array}$ & Location & $\begin{array}{l}\text { Size } \\
(\mathrm{mm})\end{array}$ & Calcifications & Giant cells \\
\hline 1 & $\mathrm{~F}$ & 4 & 3 & Right upper eyelid & 4 & + & + \\
\hline 2 & $\mathrm{~F}$ & 11 & 5 & Right upper eyelid & 5 & + & + \\
\hline 3 & $\mathrm{~F}$ & 12 & 4 & Right upper eyelid & 3 & + & + \\
\hline 4 & M & 22 & 2 & Left eyebrow & 3 & + & + \\
\hline 5 & $\mathrm{~F}$ & 7 & 24 & Left eyebrow & 5 & + & - \\
\hline 6 & $\mathrm{~F}$ & 15 & 2 & Left eyebrow & 2 & + & + \\
\hline 7 & $\mathrm{~F}$ & 51 & 4 & Right eyebrow & 5 & + & + \\
\hline 8 & $\mathrm{~F}$ & 30 & 4 & Left eyebrow & 4 & + & + \\
\hline 9 & M & 44 & 3 & Right eyebrow & 5 & + & + \\
\hline 10 & $\mathrm{~F}$ & 10 & 2 & Left eyebrow & 6 & + & + \\
\hline 11 & $\mathrm{~F}$ & 40 & 12 & Left upper eyelid & 5 & - & - \\
\hline 12 & M & 49 & 3 & Left eyebrow & 4 & + & - \\
\hline 13 & M & 65 & 60 & Left eyebrow & 3 & - & + \\
\hline 14 & M & 9 & 12 & Right eyebrow & 5 & + & - \\
\hline 15 & M & 13 & 12 & Right upper eyelid & 5 & + & + \\
\hline 16 & $\mathrm{~F}$ & 61 & 2 & Right upper eyelid & 5 & + & + \\
\hline 17 & M & 3 & 6 & Right eyebrow & 5 & + & + \\
\hline 18 & $\mathrm{~F}$ & 70 & 2 & Right upper eyelid & 8 & + & + \\
\hline 19 & M & 4 & 48 & Left eyebrow & 5 & + & - \\
\hline 20 & M & 9 & 1 & Right eyebrow & 6 & + & + \\
\hline 21 & $\mathrm{~F}$ & 13 & 1 & Right upper eyelid & 5 & + & - \\
\hline 22 & M & 48 & 6 & Right upper eyelid & 4 & + & + \\
\hline 23 & $\mathrm{~F}$ & 10 & 3 & Left upper eyelid & 5 & + & - \\
\hline 24 & M & 24 & 3 & Left upper eyelid & 8 & + & + \\
\hline 25 & $\mathrm{~F}$ & 4 & 6 & Left upper eyelid & 4 & + & + \\
\hline
\end{tabular}


The duration of lesion development ranged from 1 to 60 months (mean 9.2 months, median 3.5 months). Among the 25 patients, 8 (32\%) presented lesion at right upper eyelid, $5(20 \%)$ at right eyebrow, 4 (16\%) at left upper eyelid and $8(32 \%)$ at left eyebrow. Thus, lesion on the right eye was involved in $13(52 \%)$ cases and the eyebrow was also involved in 13 (52\%) cases (Table 1).

All the patients have presented a slowly growing, spherical, well-circumscribed single nodule. Most of the nodules had normal overlying skin, except only 1 case with ulcerated overlying skin. The tumor size (diameter in large) ranged from 2 to $8 \mathrm{~mm}$ (mean $4.76 \mathrm{~mm}$ ). None of the patients have presented multiple pilomatricomas at involved periocular sites (Table 1). The CT (computerized tomography) scan under nonenhanced mode indicated that all lesions were well-circumscribed with calcification (Fig. 1).

The follow-up histopathological observations confirmed the diagnosis of pilomatrixoma. All the tumors were composed of typical basophilic cells in the peripheral and shadow cells in the center (Fig. 2A). Meanwhile, calcifications (Fig. 2B) were found in 23 cases (92\%) and foreign body giant cells (Fig. 2C) were detected in 18 cases $(78 \%)$ (Table 1$)$.

All the patients received complete excision in the Department of Ophthalmology of our hospital. No intraoperative or postoperative complications was occurred. Moreover, no recurrence or malignant transformations were observed upon follow-up.

\section{Discussion}

Periocular pilomatrixoma is indeed an infrequent clinical condition in ophthalmic clinics[10]. To the best of our knowledge, the present study analyzed the largest case series of periocular pilomatrixoma in English literatures in recent years.

Pilomatrixoma were mostly found in female patients in the first 2 decades of their lives[1]. Our findings here were in accordance with the conclusions before (female: 56 \%,younger than 20 years: $56 \%$ ). The periocular lesions mostly develop at upper eyelids and eyebrows, without left or right predominant. We also found all tumors located at upper eyelids or eyebrows and both right and left sides were equally affected (right vs. left: $52 \%$ vs. $48 \%$ )[7-9].

In general, the gross appearance of pilomatrixoma is a kind of firm, well-circumscribed nodule with or without epidermal ulceration. Although the size of tumors varied from each other, most of the periocular pilomatrixomas were smaller than $1 \mathrm{~cm}[11]$. Upon CT scan, the lesions are always well-circumscribed and isodense relative to adjacent skeletal muscle with different degrees of calcification[12].

The tumors were composed of two kinds of typical tumors: basophilic cells at peripheral site and shadow cells at central site. Other pathologic features including calcification and foreign body giant cells[13]. The incidence of calcification ranges from $69 \%$ to $85 \%$ as reported before and the foreign body giant cells 
are always located around the calcified epithelial cell mass[3, 10]. We observed 23 cases (92\%) had calcification and 18 cases $(78 \%)$ had foreign body giant cells in their excised biopsies.

Recently, multiple pilomatricomas were noted, which are mostly related to systemic diseases like Gardner syndrome (GS), Turner syndrome (TS), etc[14]. However, to the best of our knowledge, no multiple pilomatricomas has been reported to derive from ocular adnexae till now. In our analyzed cases, no multiple pilomatricomas was found, either.

\section{Conclusion}

In summary, we analyzed 25 Chinese patients diagnosed as periocular pilomatricoma from one ophthalmic clinic in the past decade. It was confirmed that the demographic and clinical characteristics of this disease were consistent with the current knowledge.

\section{Declarations}

Acknowledgments: We are grateful to Dr. Yifei Cai (Department of Neurology, Yale University) for the assistance in English writing.

\section{Statements}

Funding: The present study was financially supported by the Science and Technology Planning Project of Jiaxing (2019AY32001).

Conflicts of interest/Competing interests: None.

Availability of data and material: All data generated or analyzed during this study are included in this published article.

Code availability (software application or custom code): None.

Author contributions: All authors contributed to the study conception and design. Material preparation, data collection and analysis were performed by Wei Song and Zhenyi Ma. The first draft of the manuscript was written by Wei Song and all authors commented on previous versions of the manuscript. All authors read and approved the final manuscript.

Ethics approval: This study was adhered to the principles listed in the Declaration of Helsinki and was approved by the Ethics Committee of Jiaxing Hospital of Traditional Chinese Medicine.

Consent to participate (include appropriate statements): Not available.

Consent for publication (include appropriate statements): Not available.

Animal Research (Ethics): Not available. 


\section{References}

1. Hu J, Yoo H, Kwon S, Kim S, Chung J, Kim H, Kim J, Yu N, Kim B (2020) Clinical analysis and review of literature on pilomatrixoma in pediatric patients. Archives of craniofacial surgery 21(5):288-293. doi:10.7181/acfs.2020.00528

2. LEVER W, GRIESEMER R (1949) Calcifying epithelioma of Malherbe; report of 15 cases, with comments on its differentiation from calcified epidermal cyst and on its histogenesis. Archives of dermatology syphilology 59(5):506-518. doi:10.1001/archderm.1949.01520300016003

3. FORBIS R, HELWIG E (1961) Pilomatrixoma (calcifying epithelioma). Archives of dermatology 83:606-618. doi:10.1001/archderm.1961.01580100070009

4. Ingraffea A (2013) Benign skin neoplasms. Facial Plast Surg Clin North Am 21(1):21-32. doi:10.1016/j.fsc.2012.11.002

5. Hada M, Meel R, Kashyap S, Jose C (2017) Eyelid pilomatrixoma masquerading as chalazion. Canadian journal of ophthalmology Journal canadien d'ophtalmologie 52(2):e62-e64. doi:10.1016/j.jcjo.2016.08.020

6. Lloyd M, Eagle R, Wasserman B (2018) Pilomatrixoma Masquerading as Giant Chalazion. Ophthalmology 125(12):1936. doi:10.1016/j.ophtha.2018.09.012

7. Levy J, Ilsar M, Deckel Y, Maly A, Anteby I, Pe'er J (2008) Eyelid pilomatrixoma: a description of 16 cases and a review of the literature. Survey of ophthalmology 53(5):526-535. doi:10.1016/j.survophthal.2008.06.007

8. Zloto O, Fabian I, Dai V, Ben Simon G, Rosner M (2015) Periocular pilomatrixoma: a retrospective analysis of 16 cases. Ophthal Plast Reconstr Surg 31(1):19-22. doi:10.1097/iop.0000000000000164

9. Herwig M, Vogel A, Holz F, Löffler K (2009) [Pilomatrixoma of the ocular adnexae: clinical and histologic analysis (13 cases)]. Klin Monatsbl Augenheilkd 226(5):404-408. doi:10.1055/s-00281109145

10. Moehlenbeck F (1973) Pilomatrixoma (calcifying epithelioma). A statistical study. Archives of dermatology 108(4):532-534. doi:10.1001/archderm.1973.01620250020004

11. Yap E, Hohberger G, Bartley G (1999) Pilomatrixoma of the eyelids and eyebrows in children and adolescents. Ophthal Plast Reconstr Surg 15(3):185-189. doi:10.1097/00002341-199905000-00008

12. Lim H, Im S, Lim G, Park H, Lee H, Sung M, Kang B, Kim J (2007) Pilomatricomas in children: imaging characteristics with pathologic correlation. Pediatric radiology 37(6):549-555. doi:10.1007/s00247007-0461-x

13. Chen H, Brownstein S, Tang T, Grynspan D, Belliveau M, El Demellawy D, O'Connor M (2019) Pilomatrixoma of the ocular adnexa: report of 3 cases with variations in the histopathological findings. Canadian journal of ophthalmology Journal canadien d'ophtalmologie 54(4):413-416. doi:10.1016/j.jcjo.2018.10.015 
14. Ciriacks K, Knabel D, Waite M (2020) Syndromes associated with multiple pilomatricomas: When should clinicians be concerned? Pediatric dermatology 37(1):9-17. doi:10.1111/pde.13947

\section{Figures}
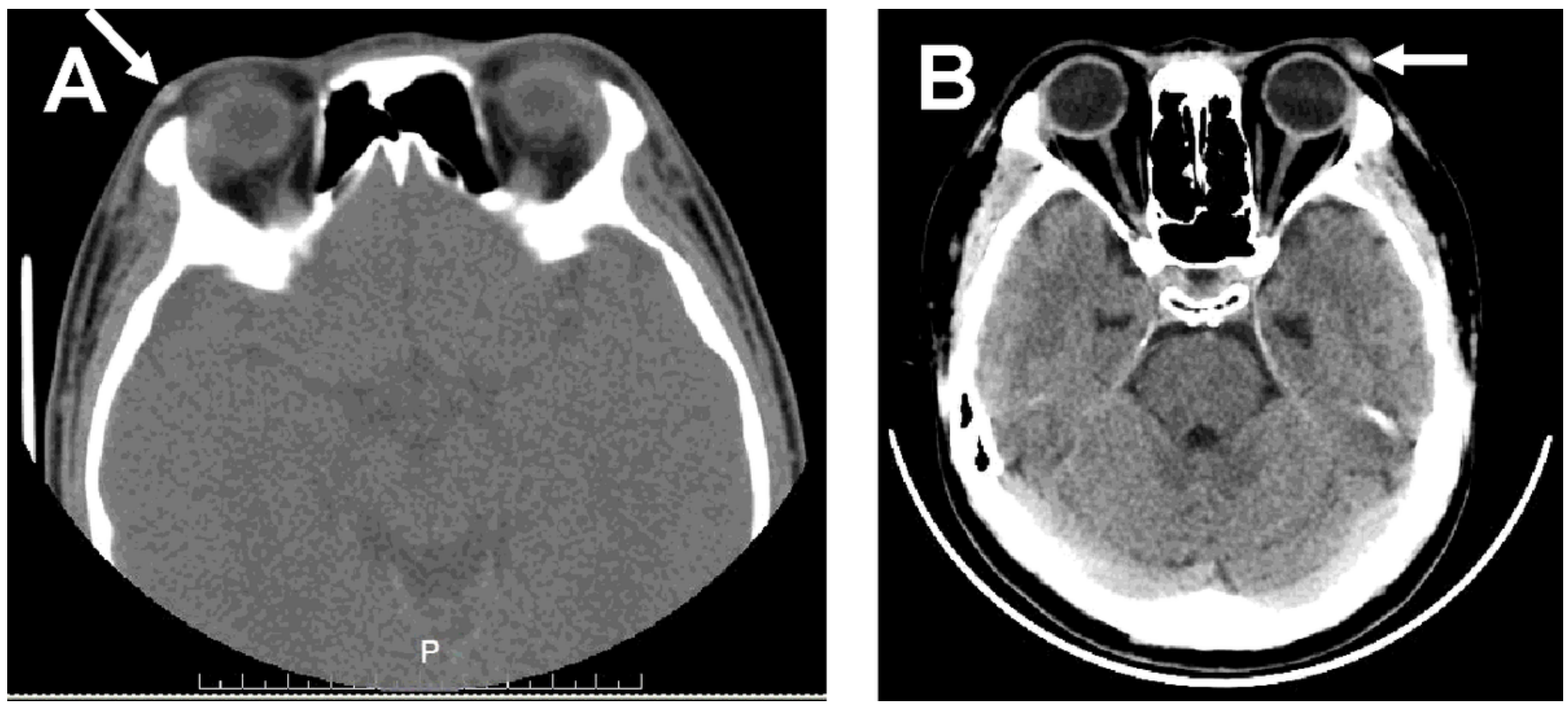

Figure 1

CT scan under nonenhanced mode indicated well-circumscribed lesions were located at right eyebrow (A) and left upper eyelid (B).
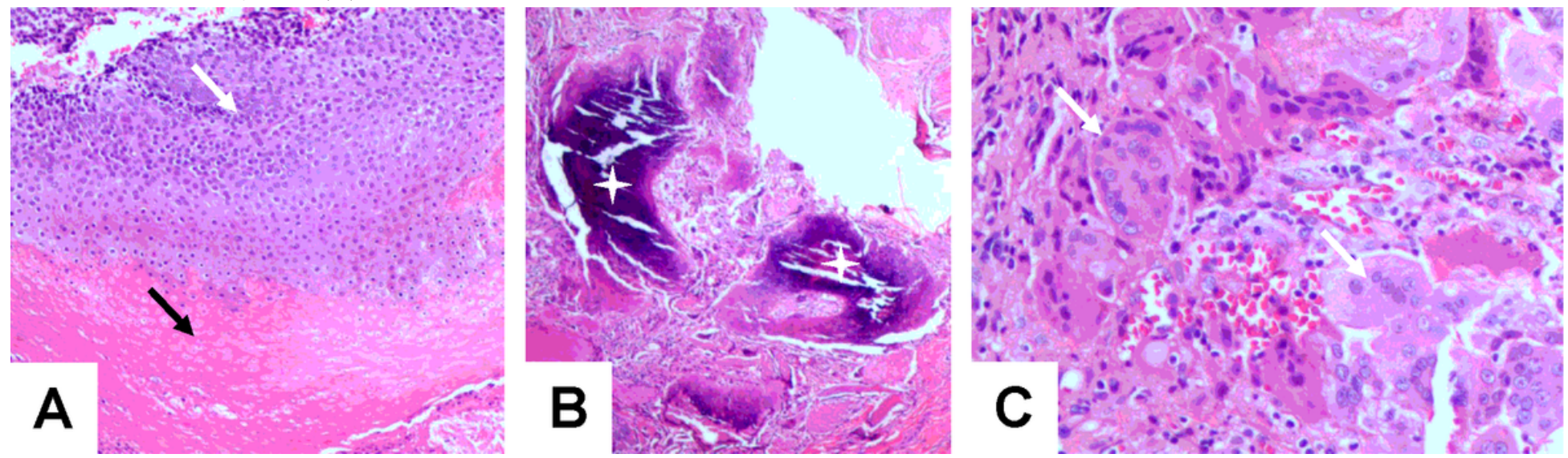

Figure 2

Histopathological features of periocular pilomatrixoma (stained with hematoxylin and eosin). (A) Basophilic cells (white arrow) and shadow cells (black arrow). (B) Calcifications (white stars). (C) foreign body giant cells (white arrows). 